\title{
Neural network unfolding of neutron spectrum measured by gold foil-based Bonner sphere
}

\author{
Najmeh Mohammadi • Hashem Miri Hakimabad • \\ Laleh Rafat Motavalli
}

Received: 28 April 2014/Published online: 2 November 2014

(C) Akadémiai Kiadó, Budapest, Hungary 2014

\begin{abstract}
Bonner sphere spectrometer (BSS) based on gold foils, as thermal neutron detectors, is one of the common device for neutron spectrometry. In this paper, the response functions of the Bonner spheres were determined for neutrons with energies ranging from thermal up to $20 \mathrm{MeV}$ using Monte Carlo code. To verify the simulated response functions, the spheres of BSS were irradiated with ${ }^{241} \mathrm{Am}-\mathrm{Be}$ neutron source at the Ferdowsi University of Mashhad and the activities of the gold foils were measured. Then the artificial neural network was applied for neutron spectrum unfolding. The results showed a good agreement between unfolded and reference spectrum of ISO 8529-1.
\end{abstract}

Keywords Bonner sphere spectrometer - Monte Carlo · Response function - Artificial neural network

\section{Introduction}

Because of the complexity of neutron interactions with the environment, precise determination of the neutron energy is quite difficult. Bonner sphere spectrometer (BSS) is one of the most frequently methods that provide an accurate measure of the neutron spectrum for neutron spectroscopy, which was introduced in 1960 [1]. This system consists of several polyethylene spheres with different diameters and thermal neutron detector in their centers. BSS has basic advantages of isotropic response and cover a wide energy range from thermal up to several of $\mathrm{MeV}$ and easy operating [2-6]. An active detector of thermal neutron, usually

N. Mohammadi · H. M. Hakimabad ( $₫)$ L L. R. Motavalli Physics Department, Faculty of Sciences, Ferdowsi University of Mashhad, Mashhad, Iran

e-mail: mirihakim@yahoo.com; mirihakim@ferdowsi.um.ac.ir proportional counter filled with ${ }^{3} \mathrm{He}$ or ${ }^{3} \mathrm{BF}$ detector, is placed at the center of these spheres. However, pulse pileup and dead time effects are drawbacks of using active detector in high intensity or pulsed radiation fields [7]. To overcome these problems, the active detectors of thermal neutron in BSS must be replaced by passive ones [8, 9]. Using gold foils as passive detector is very conventional method for thermal neutron detection [10]. Because of the insensitivity of gold foils to photons, they are very suitable for measurements in workplaces that have high photon flux and mixed fields of neutron and gamma [11].

Specific saturation activity of gold foil placed at the center of ith BS can be written as follow:

$A_{\infty_{i}}=\int R_{i}(E) \Phi(E) \mathrm{d} E$

where $\Phi(E)$ is the energy distribution of neutron and $R_{i}(E)$ is the response function of $i$ th BS. However, in practice, calculation must be done in finite number of energy intervals. Therefore, the Eq. (1) is given by;

$A_{\infty_{i}}=\sum_{j=1}^{N} R_{i j}(E) \Phi_{j}(E) \Delta E_{j}$

where $R_{i j}(E)$ is the response function of $i$ th $\mathrm{BS}$ for $E_{j}$ and $\Phi_{j}(E)$ is the neutron fluence in $E_{j}$. From the saturation activity data and response functions of BS the neutron spectrum is obtained by unfolding methods.

To unfold the neutron spectrum, several methods are used such as Monte Carlo, parameterization and iterative procedures. The prior spectrum, time-consuming procedure, the low-resolution spectrum are some drawbacks which these approaches offer [12]. Each of the mentioned difficulties has motivated the development of complementary procedures such as maximum entropy [13], 
Genetic Algorithms (GA) [14, 15] and Artificial Neural Networks (ANN) [16-18]. The use of ANN to unfold neutron spectra from the count rates measured with BSS system has become in an alternative procedure [19, 20], which has been applied with success, and some authors have expressed that this technology merit attention because of success obtained [21].

In the present work, gold foils were used as the passive detectors and matrix responses of BSS were calculated with MCNP4C [22]. Then the BSS was irradiated with ${ }^{241} \mathrm{Am}-\mathrm{Be}$ reference source at Ferdowsi University of Mashhad. Experimental and calculated activities were compared, and it was tried to unfold neutron spectrum using neural network structure.

\section{Materials and methods}

\section{Description of BSS system}

The used BSS system composed of a set of eight polyethylene spheres with density of $0.9 \mathrm{~g} / \mathrm{cm}^{3}$ and diameters of 0 (bare detector), 3.5, 4.2, 5, 6.5, 8, 10, and 12 inches. ${ }^{197} \mathrm{Au}$ foils with 99.99 purity, $1.5 \mathrm{~cm}$ diameter, and $0.1 \mathrm{~mm}$ thickness were used as passive detectors, which were placed at the center of each sphere by a holder and a support made of polyethylene. When gold foils are irradiated with neutron, ${ }^{198} \mathrm{Au}$ atoms are formed by neutron capture reaction $\left({ }^{197} \mathrm{Au}(n, \gamma){ }^{198} \mathrm{Au}\right)$ with a cross section of 98.88 barns at $0.025 \mathrm{eV} .{ }^{198} \mathrm{Au}$ atoms decay in a $\beta-\gamma$ cascade with dominant emission of $412 \mathrm{keV}$ gamma rays (with half-life of 2.7 day). After irradiation of each BS, the emitted $412 \mathrm{keV}$ gamma ray photo-peak was measured with $\mathrm{NaI}(\mathrm{Tl})$ scintillation detector and the corresponding activity was calculated.

The $\mathrm{NaI}(\mathrm{Tl})$ detector was a cylindrical scintillation with 3 inch height and 3 inch diameter from Canberra (model 802-4). The energy resolution of this detector was $7.5 \%$, which were specified at $662 \mathrm{keV}$ of ${ }^{137} \mathrm{Cs}$. Its efficiency was also calculated with MCNP simulation.

\section{Measurement of gold activity}

The specific saturation activity, in $\mathrm{Bq} / \mathrm{g}$, of the activated gold foil inside the ith sphere can be obtained by following equation:

$A_{\infty_{i}}=\frac{\lambda t_{m} C}{m q \varepsilon} \frac{e^{\lambda t_{w}}}{\left(1-e^{-\lambda t_{i}}\right)\left(1-e^{-\lambda t_{m}}\right)}$

where $\lambda$ is the decay constant of ${ }^{198} \mathrm{Au}\left(2.97 \times 10^{-6}\right.$ per second), $q$ is its branching ratio (0.995), $C$ is the net area at $412 \mathrm{keV}$ photo-peak after background and dead time corrections, $\varepsilon$ is the detector efficiency calculated with
MCNP4C, $t_{m}, t_{i}$ and $t_{w}$ are the measurement time, irradiation time, and elapsed time between irradiation and measurement time, respectively. For background correction in each situation, the background spectrum was measured in the same amount of measurement time and was subtracted from the gamma spectrum of activated gold foil.

\section{$\mathrm{NaI}(\mathrm{Tl})$ detector efficiency}

The $\mathrm{NaI}(\mathrm{Tl})$ detector was calibrated in energy using standard reference sources. Since it is difficult to have a standard source with the emitted gamma rays of $412 \mathrm{keV}$, as the active gold foils, $\mathrm{NaI}(\mathrm{Tl})$ detector efficiency was determined by simulation. For this purpose, a cylinder with diameter and height of $3^{\prime \prime}$ together with its aluminum cover of $0.05 \mathrm{~cm}$ thickness was modeled. Gold foil and its holder were also placed at $1 \mathrm{~mm}$ distance from the detector. The emitted gamma spectrum of the activated gold foil was used for SDEF card in the MCNP input. F8 tally (pulseheight estimate) was applied to acquire the deposited energy distribution of gamma in the detector. FT card was entered in the input file to include Gaussian Energy Broadening (GEB) treatment and $2 \mathrm{keV}$ energy bin was selected to have a better resolution. Gaussian Energy Broadening (GEB) is a special treatment for tallies, to better simulate a physical radiation detector, in which energy peaks exhibit GEB. GEB is called by entering FTn card in the input file of MCNP. The tallied energy is broadened by sampling from the Gaussian:

$f(E)=D e^{-\left(\frac{E-E_{0}}{A}\right)^{2}}$

where $E, E_{0}, D$, and $A$ are the broadened energy, the unbroadened energy of the tally; a normalization constant, and the Gaussian width, respectively.

The Gaussian width is related to the full width half maximum (FWHM) by $A=\frac{\text { FWHM }}{2 \sqrt{\ln 2}}$. The desired FWHM is specified by the user-provided constants, $a, b$, and $c$, where:

$\mathrm{FWHM}=a+b \sqrt{E+c E^{2}}$

The units of $a, b$, and $c$ are $\mathrm{MeV}, \mathrm{MeV}^{1 / 2}$, and none, respectively. The FWHM is defined as FWHM $=2$ (EFWHM $-E_{\mathrm{o}}$, where EFWHM is such that $f(\mathrm{EFWHM})=$ $f\left(E_{\mathrm{o}}\right)$ and $f\left(E_{\mathrm{o}}\right)$ is the maximum value of $f(E)$. Four standard $\gamma$-ray sources $\left({ }^{137} \mathrm{Cs},{ }^{60} \mathrm{Co},{ }^{22} \mathrm{Na},{ }^{198} \mathrm{Au}\right)$ were used to determine $a, b$, and $c$ as parameters which specify the Full Width at Half Maximum in the GEB option.

Therefore the parameters of $a=0.0266 \mathrm{MeV}$, $b=0.02327 \mathrm{MeV}^{1 / 2}, c=0.97511$ were used in the GEB option to generate detector responses.

Statistical uncertainties of calculation were less than $1 \%$. After plotting the output of F8 tally in terms of 


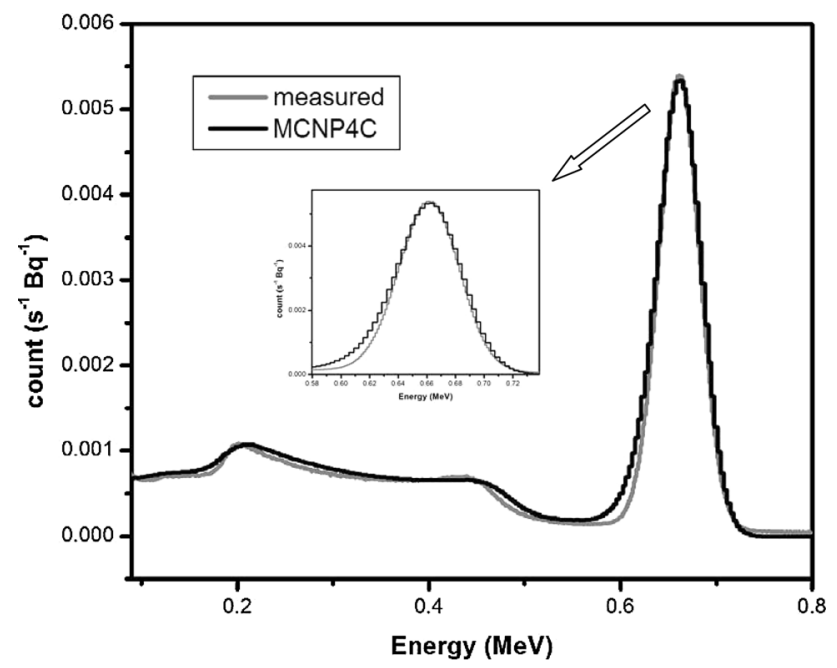

Fig. 1 Measured and MCNP4C of ${ }^{137} \mathrm{CS}$ spectra obtained for the NaI (Tl) detector

energy, the area under the peak of $412 \mathrm{keV}$ was specified as the efficiency of $\mathrm{NaI}(\mathrm{Tl})$ detector at this energy. With this method, its value was obtained 0.2. To ensure that the result of MCNP4C was accurate, the measured and calculated spectra of a standard source of ${ }^{137} \mathrm{Cs}$ were compared in units of count rates per standard source activities in the Fig. 1. As shown, the spectrum obtained by MCNP4C simulation matched very well with measured spectrum, especially in the region of photo-peak, so that the deviation in photo-peak area was $2 \%$. Considering this good agreement, the MCNP calculations were validated for calculating the efficiency of detector.

\section{Simulation of response functions}

We calculated the response functions of eight spheres with MCNP4C simulation for 26 neutron energy intervals, which were equally spaced in the logarithmic scale from $10^{-9}$ to $10^{-1} \mathrm{MeV}$ (10 bins) and $10^{-1}$ to $20 \mathrm{MeV}$ (10 bins) and other 6 bins were selected based on the characteristic peaks of ${ }^{197} \mathrm{Au}$, which are observed in bare configuration. For this purpose, a disk source of mono-energetic neutron with the same diameter of each sphere and parallel to gold foil surface was considered. To determine response functions independent of the source-to-Bonner sphere distance, simulations were performed in the vacuum space. $S(\alpha, \beta)$ treatment was also used to account thermal neutron scattering in the polyethylene.

The reaction rate was obtained from $\Sigma \Phi$, where $\Phi$ is the neutron spectra, and $\Sigma$ is the macroscopic cross section of interested reaction. So the response of each sphere $R(E)$, the number of radioactive capture reaction ${ }^{197} \mathrm{Au}(n, \gamma)$ ${ }^{198} \mathrm{Au}$ in gold foil, can be written as:

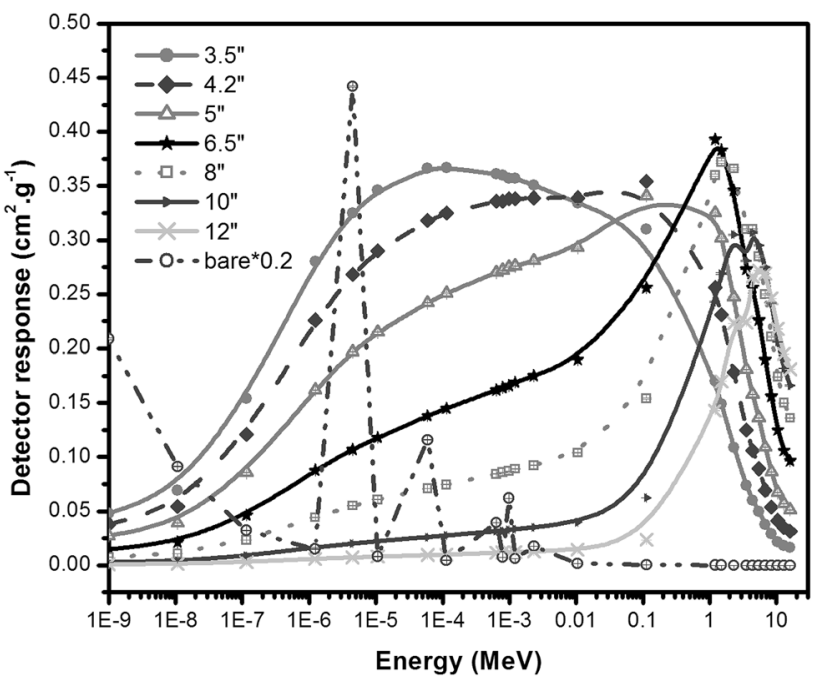

Fig. 2 The simulated response functions of BSS with MCNP4C

$$
\begin{gathered}
R_{i}(E)=S_{i} V N \int \sigma \Phi_{\mathrm{E}} \mathrm{d} E=C_{i} \int \sigma \Phi_{\mathrm{E}} \mathrm{d} E \\
i=1,2, \ldots, \text { number of spheres }
\end{gathered}
$$

where $S_{i}$ is the area of source, $V$ is the volume of gold foil, $N$ is the volumetric atom density (atom/barn/cm), $\sigma$ is the microscopic cross section of ${ }^{197} \mathrm{Au}(n, \gamma){ }^{198} \mathrm{Au}$ reaction (in barn) and $C_{i}$ is the product of $S_{\mathrm{i}}, V$, and $N$. To calculate the response functions, the F4 tally was used together with FM4 card (by option of $C_{i}$ ). The average of $5 \times 10^{8}$ neutrons were transported to reach the statistical uncertainties less than $1 \%$ for the response functions of all spheres and energies.

The simulated response functions of eight configurations of BSS are presented in Fig. 2. It is observed that by increasing the diameter of polyethylene sphere, the maximum response is shifting to the higher energies. It can be clearly seen that the applied BSS has a very large energy range and is suitable to use in neutron spectrometry at pulsed and high intensity mixed fields.

\section{Experimental measurement}

In order to verify the computed response function with MCNP4C, a set of irradiations were done with ${ }^{241} \mathrm{Am}-\mathrm{Be}$ neutron source. All of the eight configurations were placed with an average distance of about $40 \mathrm{~cm}$ from neutron source and were exposed for $20-22 \mathrm{~h}$. The ${ }^{241} \mathrm{Am}-\mathrm{Be}$ source $(50 \mathrm{~mm}$ in height and $30 \mathrm{~mm}$ in diameter) with activity of $3.95 \mathrm{Ci}$ was used. The length, width, and height of laboratory were $8.5,9$, and $4 \mathrm{~m}$, respectively with $40 \mathrm{~cm}$ concrete walls. The source distance from the floor was chosen $180 \mathrm{~cm}$ to minimize the neutron scattering. After irradiation, the photo-peak net area count rates of activated gold foils were measured with $\mathrm{NaI}(\mathrm{Tl})$ detector for 5-7 h. 


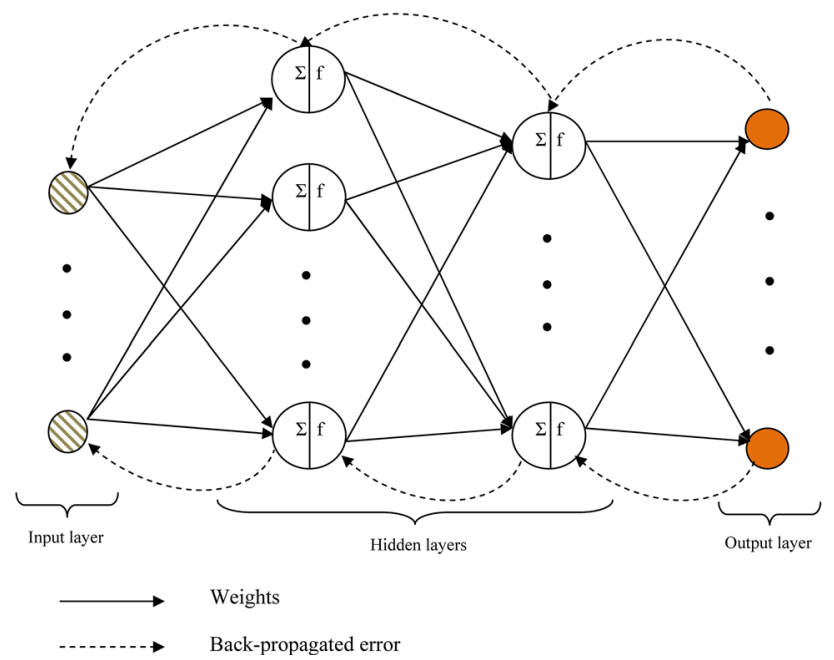

Fig. 3 Neurons and weights in a feed forward back-propagation artificial neural network with two hidden layers

On the other hand, activities of gold foils were also calculated by folding the simulated response matrix with the neutron spectrum of the ${ }^{241} \mathrm{Am}-\mathrm{Be}$ neutron taken from the ISO standard 8529-1 using Eq. (2) [23].

Neural network

Artificial Neural Networks (ANN) Neural networks are composed of simple elements operating in parallel. These elements are inspired by biological nervous systems. As in nature, the network function is determined largely by the connections between elements. We can train a neural network to perform a particular function by adjusting the values of the connections (weights) between elements [24]. A neural network has three type layers; input, hidden, and output layers. Each layer has several neurons that are connected with other neurons through weights and biases. Layers are also connected together with activation functions. During ANN training, a set of data, with input and output information, is employed and the neuron weights are adjusted until the pattern between input and output data is achieved. The ANN learning algorithm is the adaptation process to define and modify the weights and biases. The training has the purpose of selecting the weight that adapts better to the network in relation to the training data [25]. A schematic diagram of a neural network was shown in the Fig. 3.

\section{Results and discussion}

Validation of the response functions

The measured and calculated activities with their errors were compared in Table 1. The errors of measured values
Table 1 Measured and calculated activities of gold foils placed at the center of Bonner Sphere $(\mathrm{Bq} / \mathrm{g})$

\begin{tabular}{lccc}
\hline $\begin{array}{l}\text { Diameter } \\
\text { of sphere }\end{array}$ & $\begin{array}{l}\text { Measured } \\
\text { activity } \\
(\mathrm{Bq} / \mathrm{g})\end{array}$ & $\begin{array}{l}\text { Calculated } \\
\text { activity } \\
\text { (Bq/g) }\end{array}$ & $\begin{array}{l}\text { Measured } \\
\text { to calculated } \\
\text { ratio }\end{array}$ \\
\hline $0^{\prime \prime}$ & $1.13 \pm 0.03$ & $0.94 \pm 0.05$ & $1.2 \pm 0.03$ \\
$3.5^{\prime \prime}$ & $46 \pm 1.5$ & $40 \pm 0.3$ & $1.15 \pm 0.04$ \\
$4.2^{\prime \prime}$ & $76 \pm 2.4$ & $66 \pm 0.1$ & $1.15 \pm 0.04$ \\
$5^{\prime \prime}$ & $85 \pm 2.2$ & $74 \pm 0.2$ & $1.15 \pm 0.03$ \\
$6.5^{\prime \prime}$ & $196 \pm 5.2$ & $178 \pm 0.3$ & $1.10 \pm 0.03$ \\
$8^{\prime \prime}$ & $113 \pm 3$ & $111 \pm 0.2$ & $1.01 \pm 0.03$ \\
$10^{\prime \prime}$ & $106 \pm 2.7$ & $105 \pm 0.3$ & $1.01 \pm 0.03$ \\
$12^{\prime \prime}$ & $60 \pm 1.5$ & $58 \pm 0.03$ & $1.03 \pm 0.03$ \\
\hline
\end{tabular}

were calculated based on Eq. (3). As recommended by the ISO-8529/2 the measured data should be corrected for the effect of the finite size of source or detector [26]. This correction is made by means of geometry factor, $F(1)$. For a point source irradiating a spherical detector, the geometry factor is calculated as follow:

$F(l)=1+\delta\left(\frac{r_{D}}{2 l}\right)^{2} \quad\left(\right.$ for $\left.l / r_{D}>2\right)$

where $l$ is the distance from the source center to detector center, $r_{D}$ is the detector radius, and $\delta$ is the neutron effectiveness parameter. The quantity $\delta$ has been shown to depend slightly on $r_{D}$; the recommended value for all cases is $\delta=0.5 \pm 0.1$. For the used source-detector distance of $40 \mathrm{~cm}$ and the diameter of detector (gold foil diameter of $1.5 \mathrm{~cm}$ ), the geometry factor was obtained almost equal to one, and then this factor was not applied on the measurements. As seen in Table 1, the gold activation without Bonner sphere (bare) was very small duo to slight contribution of thermal neutrons in ${ }^{241} \mathrm{Am}-\mathrm{Be}$ spectrum. The results showed a good agreement between experimental and calculated activities for 8,10 , and $12^{\prime \prime}$ spheres whilst, the other spheres showed a 10-15\% deviations. The reason of this behavior is that the scattered neutrons from the room affected the response of smaller spheres. To prove this claim, the effect of considering room in the simulations on the activities of gold foils was determined using MCNP (Table 2). It can be seen that the effect of room scattering on the larger sphere is lower than for smaller sphere. Regarding the results from the following comparisons and small contribution of room scattering in gold activation, the room effect was not taken into calculations. It can be also concluded that the response functions for the three largest spheres can be considered very accurate. For more validation, the MCNP calculations were performed using ${ }^{252} \mathrm{Cf}$ and ${ }^{252} \mathrm{Cf}+\mathrm{D}_{2} \mathrm{O}$ as neutron sources. Then the gold foil activities were compared with those obtained by Eq. (2) 
Table 2 The effect of room scattering on the activities of gold foils placed at the center of Bonner Sphere irradiated with ${ }^{241} \mathrm{Am}-\mathrm{Be}$ source $(\mathrm{Bq} / \mathrm{g} / \mathrm{n})$ (The results of the bare detector were not reported due to high statistical error)

\begin{tabular}{llll}
\hline $\begin{array}{l}\text { Diameter } \\
\text { of sphere }\end{array}$ & $\begin{array}{l}\text { Calculated } \\
\text { activity }(\mathrm{Bq} / \mathrm{g} / \mathrm{n}) \\
\text { (without room) }\end{array}$ & $\begin{array}{l}\text { Calculated } \\
\text { activity } \\
(\mathrm{Bq} / \mathrm{g} / \mathrm{n}) \\
\text { (with room) }\end{array}$ & $\begin{array}{l}\text { calculated } \\
\text { activity } \\
\text { with room } \\
\text { to without } \\
\text { room ratio }\end{array}$ \\
\hline $3.5^{\prime \prime}$ & $5.2 \mathrm{E}-06 \pm 1 \mathrm{E}-07$ & $5.5 \mathrm{E}-06 \pm 2 \mathrm{E}-07$ & 1.06 \\
$4.2^{\prime \prime}$ & $8.6 \mathrm{E}-06 \pm 2 \mathrm{E}-07$ & $9.1 \mathrm{E}-06 \pm 2 \mathrm{E}-07$ & 1.05 \\
$5^{\prime \prime}$ & $9.5 \mathrm{E}-06 \pm 1 \mathrm{E}-07$ & $1.02 \mathrm{E}-05 \pm 2 \mathrm{E}-07$ & 1.07 \\
$6.5^{\prime \prime}$ & $2.19 \mathrm{E}-05 \pm 2 \mathrm{E}-07$ & $2.26 \mathrm{E}-05 \pm 2 \mathrm{E}-07$ & 1.03 \\
$8^{\prime \prime}$ & $1.26 \mathrm{E}-05 \pm 1 \mathrm{E}-07$ & $1.29 \mathrm{E}-05 \pm 3 \mathrm{E}-07$ & 1.02 \\
$10^{\prime \prime}$ & $1.18 \mathrm{E}-05 \pm 1 \mathrm{E}-07$ & $1.2 \mathrm{E}-05 \pm 2 \mathrm{E}-07$ & 1.01 \\
$12^{\prime \prime}$ & $6.59 \mathrm{E}-06 \pm 7 \mathrm{E}-07$ & $6.7 \mathrm{E}-06 \pm 1 \mathrm{E}-07$ & 1.02 \\
\hline
\end{tabular}

and corresponding spectra taken from the ISO standard 8529-1. Considering the results in Table 3, the calculated response functions were validated.

\section{Neutron spectra}

Providing the appropriate data for ANN training has an important role to reach the best results. So, using the Monte Carlo code MCNP4C 100 neutron spectra with 26 energy groups were produced for training data as target. To this end, ${ }^{241} \mathrm{Am}-\mathrm{Be},{ }^{252} \mathrm{Cf}$ and mono energetic sources were placed in the center of various spheres of different elements such as beryllium, iron, cooper, water, graphite, concrete,

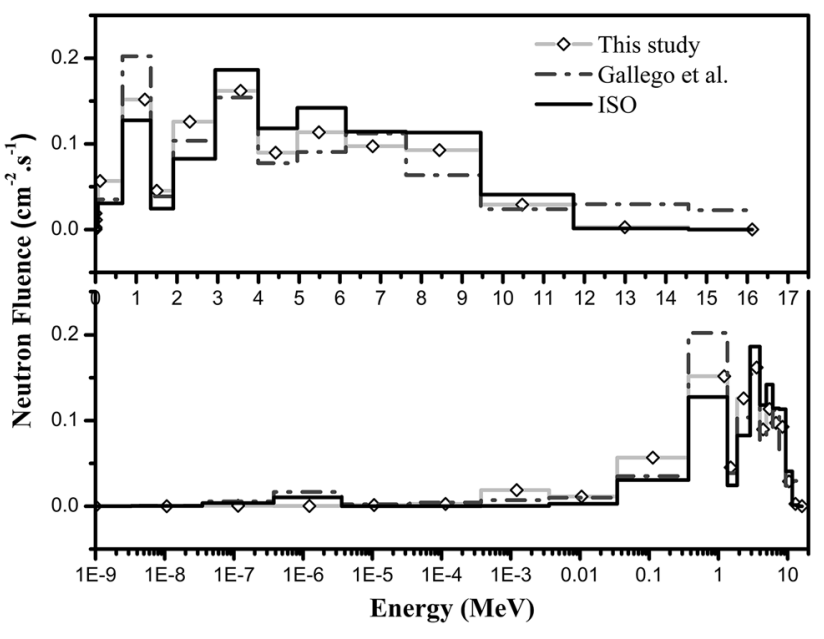

Fig. 4 Comparison between ${ }^{241} \mathrm{Am}-\mathrm{Be}$ neutron spectrum of ISO and ANN output

tungsten, bismuth, and aluminum. Then, using the response matrix and Eq. (2), activities of gold foils in the 7 spheres and bare were calculated as the input data for training.

In this study, we used the nntool of matlab 2012a software [24]. The feed forward back-propagation network was used for our problem. This means that the artificial neurons are organized in layers, and send their signals "forward", and then the errors are propagated backwards. Training function of TRAINRP, adaption learning function of LEARNGD and performance function of MSE (Mean squared error) were used for ANN spectroscopy. In the used ANN data division was random, so that the $60 \%$ of

Table 3 Calculated activities of gold foils irradiated by ${ }^{252} \mathrm{Cf}$ and ${ }^{252} \mathrm{Cf}+\mathrm{D}_{2} \mathrm{O}$ sources $(\mathrm{Bq} / \mathrm{g} / \mathrm{n})$

\begin{tabular}{cccc}
\hline source & $\begin{array}{l}\text { Diameter } \\
\text { of sphere } \\
\text { (inch) }\end{array}$ & $\begin{array}{l}\text { Calculated activity } \\
(\mathrm{Bq} / \mathrm{g} / \mathrm{n})(\mathrm{MCNP})\end{array}$ & $\begin{array}{l}\text { Calculated activity } \\
(\mathrm{Bq} / \mathrm{g} / \mathrm{n})(\mathrm{eq} .2)\end{array}$ \\
\hline${ }^{252} \mathrm{Cf}$ & 0 & $8.9 \mathrm{E}-08 \pm 3 \mathrm{E}-09$ & $7.92 \mathrm{E}-08 \pm 3 \mathrm{E}-10$ \\
& 3.5 & $1.40 \mathrm{E}-05 \pm 3 \mathrm{E}-08$ & $1.95 \mathrm{E}-05 \pm 6 \mathrm{E}-08$ \\
& 4.2 & $2.03 \mathrm{E}-05 \pm 6 \mathrm{E}-08$ & $2.44 \mathrm{E}-05 \pm 5 \mathrm{E}-08$ \\
& 5 & $2.60 \mathrm{E}-05 \pm 3 \mathrm{E}-08$ & $2.96 \mathrm{E}-05 \pm 1 \mathrm{E}-07$ \\
& 6.5 & $3.01 \mathrm{E}-05 \pm 6 \mathrm{E}-08$ & $2.82 \mathrm{E}-05 \pm 1 \mathrm{E}-07$ \\
& 8 & $2.81 \mathrm{E}-05 \pm 6 \mathrm{E}-08$ & $1.46 \mathrm{E}-05 \pm 65 \pm 1 \mathrm{E}-07$ \\
& 10 & $2.09 \mathrm{E}-05 \pm 6 \mathrm{E}-08$ & $7.63 \mathrm{E}-06 \pm 3 \mathrm{E}-08$ \\
${ }^{252} \mathrm{Cf}+\mathrm{D}_{2} \mathrm{O}$ & 12 & $1.41 \mathrm{E}-05 \pm 4 \mathrm{E}-08$ & $2.48 \mathrm{E}-05 \pm 7 \mathrm{E}-08$ \\
& 0 & $7.99 \mathrm{E}-06 \pm 2 \mathrm{E}-08$ & $2.56 \mathrm{E}-05 \pm 5 \mathrm{E}-08$ \\
& 3.5 & $2.54 \mathrm{E}-05 \pm 2 \mathrm{E}-08$ & $2.36 \mathrm{E}-05 \pm 7 \mathrm{E}-08$ \\
& 4.2 & $2.57 \mathrm{E}-05 \pm 2 \mathrm{E}-08$ & $1.91 \mathrm{E}-05 \pm 6 \mathrm{E}-08$ \\
& 5 & $2.41 \mathrm{E}-05 \pm 4 \mathrm{E}-08$ & $1.39 \mathrm{E}-05 \pm 4 \mathrm{E}-08$ \\
& 6.5 & $1.81 \mathrm{E}-05 \pm 5 \mathrm{E}-08$ & $8.40 \mathrm{E}-06 \pm 2 \mathrm{E}-08$ \\
& 8 & $1.22 \mathrm{E}-05 \pm 4 \mathrm{E}-08$ & $5.11 \mathrm{E}-06 \pm 2 \mathrm{E}-08$
\end{tabular}


Table 4 The parameters of ANNs which had minimum value of MSE

\begin{tabular}{|c|c|c|c|c|}
\hline Training function & Learning function & Performance function & Transfer function & MSE \\
\hline TRAINRP (Resilient backpropagation) & $\begin{array}{l}\text { LEARNGD (Gradient descent } \\
\text { weight/bias learning } \\
\text { function) }\end{array}$ & $\begin{array}{l}\text { MSE (Mean squared } \\
\text { error) }\end{array}$ & $\begin{array}{l}\text { TANSIG (Hyperbolic } \\
\text { tangent sigmoid) }\end{array}$ & 0.01 \\
\hline $\begin{array}{l}\text { TRAINCGP (Polak-Ribiere conjugate } \\
\text { gradient backpropagation) }\end{array}$ & LEARNGD & $\begin{array}{l}\text { SSE (Sum squared } \\
\text { error) }\end{array}$ & LOGSIG (Log sigmoid) & 0.05 \\
\hline TRAINBR (Bayesian regularization) & $\begin{array}{l}\text { LEARNGDM (Gradient } \\
\text { descent with momentum } \\
\text { weight/bias learning } \\
\text { function) }\end{array}$ & MSE & TANSIG & 0.05 \\
\hline $\begin{array}{l}\text { TRAINCGB (Powell-Beale conjugate } \\
\text { gradient backpropagation) }\end{array}$ & LEARNGDM & SSE & TANSIG & 0.06 \\
\hline $\begin{array}{l}\text { TRAINBFG (BFGS quasi-Newton } \\
\text { backpropagation) }\end{array}$ & LEARNGD & MSE & LOGSIG & 0.06 \\
\hline $\begin{array}{l}\text { TRAINGD (Gradient descent } \\
\text { backpropagation) }\end{array}$ & LEARNGDM & $\begin{array}{l}\text { MSEREG (Mean } \\
\text { squared error with } \\
\text { regularization) }\end{array}$ & LOGSIG & 0.06 \\
\hline $\begin{array}{l}\text { TRAINCGF (Fletcher-Powell conjugate } \\
\text { gradient backpropagation) }\end{array}$ & LEARNGDM & SSE & TANSIG & 0.09 \\
\hline
\end{tabular}

the samples were assigned to the training set, $20 \%$ to the validation set, and $20 \%$ to the test set. After trying various structures of ANN, the ANN topology of 8:20:36:26, which represents the number of neurons in the input, first hidden, second hidden, and output layers, was selected as an appropriate network structure, which was acceded with minimum performance function and had maximum compatibility with ISO-recommended spectra. The activation function of TANSIG (hyperbolic tangent sigmoid), which is a non-linear transfer function to train the multi-layer neural networks, was used in this ANN. This unfolded spectrum was found after $10^{5}$ iterations and performance value of $1.72 \mathrm{E}-5$. The comparison between ISO spectra and the neutron spectra obtained with this topology was shown in the Fig. 4. As seen, the unfolded spectrum have a good agreement with ISO. Our results were also compared with those reported by Gallego et al. [27]. Although some similarities were observed between these two spectra, but there were some differences in the $0.5-1.5 \mathrm{MeV}$ and 4-10 MeV energy bins. These differences are due to their different neural network and training data.

Another comparing between ISO spectra $\left[\Phi(E)^{\mathrm{ISO}}\right]$ with those unfolded with the $\mathrm{ANN}\left[\Phi(E)^{\mathrm{ANN}}\right]$ was obtained by calculating the root mean square error (MSE) using

$\mathrm{MSE}=\sqrt{\frac{1}{N} \sum_{1}^{N}\left(\Phi(E)_{i}^{\mathrm{ANN}}-\Phi(E)_{i}^{\mathrm{ISO}}\right)^{2}}$

The calculated MSE for unfolded spectra was 0.017 . This small value is indicating the agreement between these two spectra.

The outcomes of ANN are too sensitive to the training algorithm, learning function, transfer (activation) and performance function. Therefore, 10 training algorithms, 3 activation functions, 2 learning functions, and 3 performance functions were tested (totally 126 cases). The results showed that the activation function of PURELINE is not appropriate for neutron spectrometry, generally. The parameters of ANN, which have the minimum value for MSE were summarized in the Table 4. Regarding the achieved results, the minimum MSE relates to the ANN used in this study with TRAINRP, LEARNGD, and TANSIG as the training algorithm, learning function, and activation function, respectively.

Therefore, the neural network is able to predict the spectrum with a good accordance with the reference one.

\section{Conclusion}

The passive Bonner sphere spectrometer based on gold foil activation is an efficient method for neutron spectrum measurement in pulsed and mixed $(n-\gamma)$ fields. In our experimental setup, we used eight polyethylene spheres with different diameter and gold foils with average diameter and thickness of $1.5 \mathrm{~cm}$ and $0.1 \mathrm{~mm}$. Response matrix was simulated with MCNP4C code for neutron energies from $10^{-9}$ to $20 \mathrm{MeV}$. All of spheres were irradiated by ${ }^{241} \mathrm{Am}-\mathrm{Be}$ source in sufficient times. After irradiation, the activity of gold foils were measured with $\mathrm{NaI}(\mathrm{Tl})$ detector. Then the values of activity obtained from measurement and calculation were compared. In this work, we used neural network for unfolding the neutron spectra of ${ }^{241} \mathrm{Am}-\mathrm{Be}$ source. To this end, the ANN topology of 8:20:36:26 has the most acceptable outcome. The obtained results indicate that the neural network can be considered as an interesting 
alternative and promising tool for neutron spectrum unfolding using a BSS.

\section{References}

1. Bramblett RL, Ewing RI, Bonner TW (1960) A new type of neutron spectrometer. Nucl Instrum Methods 9(1):1-12

2. Alevra AV, Thomas DJ (2003) Neutron spectrometry in mixed fields: multisphere spectrometers. Radiat Prot Dosim 107(1-3):37-72

3. Bedogni R, Ferrari P, Gualdrini G, Esposito A (2010) Design and experimental validation of a Bonner sphere spectrometer based on dysprosium activation foils. Radiat Meas 45(10):1201-1204

4. Braga CC, Dias MS (2002) Application of Neural Networks for unfolding neutron spectra measured by means of Bonner spheres. Nucl Instrum Methods A 476(1):252-255

5. Vylet V (2002) Response matrix of an extended Bonner sphere system. Nucl Instrum Methods A 476(1-2):26-30

6. Khabaz R, Miri SH (2011) Development of a Bonner sphere spectrometer with emphasis on decreasing the contribution of scattering by using a new designed shadow cone. J Radioanal Nucl Chem 289:789-794

7. Vega Carrillo HR, Wehring BW, Veinot KG, Hertel NE (1999) Response matrix for a multi sphere spectrometer using a 6 lif thermoluminescence dosemeter. Radiat Prot Dosim 81(2):133-140

8. Mazrou H, Idiri Z, Sidahmed T, Allab M (2010) MCNP5 evaluation of a response matrix of a Bonner sphere spectrometer with a high efficiency 6LiI $(\mathrm{Eu})$ detector from $0.01 \mathrm{eV}$ to $20 \mathrm{MeV}$ neutron. J Radioanal Nucl Chem 284:253-263

9. Vega-Carrillo HR, Ortiz-Hernandez A, Hernandez-Davila VM, Hernandez-Almaraz B, Teodoro RM (2010) $\mathrm{H}^{*}(10)$ and neutron spectra around LINACs. J Radioanal Nucl Chem 283:537-540

10. Thomas DJ, Bardell AG, Macaulay EM (2002) Characterization of a gold foil-based Bonner sphere set and measurements of neutron spectra at a medical accelerator. Nucl Instrum Methods A 476:31-35

11. Wang Z, Hutchinson JD, Hertel NE, Burgett E, Howell RM (2008) Study of a gold-foil-based multi sphere neutron spectrometer. Radiat Prot Dosim 128(3):289-293

12. Lindemann L, Zech G (1995) Unfolding by weighting Monte Carlo events. Nucl Instrum Methods Phys ResA 354:516-521

13. Reginatto M, Goldhagen P, Neumann S (2002) Spectrum unfolding sensitivity analysis and propagation of uncertainties with the maximum entropy deconvolution code MAXED. Nucl Instrum Methods Phys Res A 476(1-2):242-246

14. Freeman DW, Edwards DR, Bolon AE (1999) Genetic algorithmsa new technique for solving the neutron spectrum unfolding problem. Nucl Instrum Methods Phys Res A 425(3):549-576

15. Mukherjee B (2002) A high-resolution neutron spectra unfolding method using the genetic algorithm technique. Nucl Instrum Methods Phys Res A 476(1-2):247-251

16. Sharghi Ido A, Bonyadi MR, Etaati GR, Shahriari M (2009) Unfolding the neutron spectrum of a NE213 scintillator using artificial neural networks. Appl Radiat Isot 67(10):1912-1918

17. Ortiz R, Martinez B, Vega C, Gallego D, Lorente F, Mendez V, Los Arcos M, Guerrero A (2011) Performance of artificial neural networks and genetical evolved artificial neural networks unfolding techniques. Rev Mex De Fis S 57(1):89-92

18. Kardan MR, Setayeshi S, Koohi-Fayegh R, Ghiassi-Nejad M (2003) Neutron spectra unfolding in Bonner spheres spectrometry using neural networks. Radiat Prot Dosim 104(1):27-30

19. Rosario MB, Manuel ORJ G, Vega-Carrillo HR (2008) A new computer tool based on ANN technology, applied in neutron spectrometry and dosimetry research areas, IEEE 189-194

20. Ortiz-Rodriguez JM, Reyes Alfaro A, Reyes Haro A, Cervantes Viramontes JM, Vega-Carrillo HR (2014) A neutron spectrum unfolding computer code based on artificial neural networks. Radiat Phys Chem 95:428-431

21. Begdoni R, Domingo C, Esposito A, Frenandez F (2007) FRUIT: an operational tool for multi sphere neutron spectrometry in workplaces. Nucl Instrum Methods Phys Res A 580:1301-1309

22. Briesmeister JF (2000) A general Monte Carlo N-particle transport code. Los Alamos National Laboratory Report LA-13709-M MCNPTM

23. ISO 8529-1 (2001) Reference neutron radiations-part 1: characteristic and methods of productions. International Organization for Standardization, Geneva

24. Demuth H, Beale M (2002) Neural network toolbox for use with MATLAB, User guide version 4 (The Math Works, Inc.)

25. Vega-Carrillo HR, Hernandez Davila VM, Manzanares AE, Gallego E, Lorente A, Iniguez MP (2007) Artificial neural networks technology for neutron spectrometry and dosimetry. Radiat Prot Dosim 126:408-412

26. ISO 8529-2 (2000) Reference neutron radiations-part 2: calibration fundamentals of radiation protection devices related to the basic quantities characterizing the radiation field. International Organization for Standardization, Geneva

27. Gallego E, Lorente A, Vega-Carrillo HR (2004) Characteristics of the neutron field of the facility at DIN-UPM. Radiat Prot Dosim 110:73-79 